\title{
Is resistance to ischaemic conduction failure induced by hypoxia?
}

\author{
E. A. Masson ${ }^{1}$, S.E. Church ${ }^{1}$, A. A. Woodcock ${ }^{2}$, S.P. Hanley ${ }^{3}$ and A.J. M. Boulton ${ }^{1}$ \\ ${ }^{1}$ Manchester Royal Infirmary, ${ }^{2}$ Wythenshawe Hospital, ${ }^{3}$ Monsall Hospital, Manchester, UK
}

\begin{abstract}
Summary. Resistance to ischaemic conduction failure is a recognised but unexplained property of diabetic peripheral nerve. We have studied matched groups of control, diabetic, and non-diabetic hypoxic subjects (hypoxia: arterial oxygen tension $\leqslant 60 \mathrm{~mm} \mathrm{Hg}(8 \mathrm{kPa})$ on at least one occasion and secondary to chronic lung disease). Similar resistance to ischaemia was seen in the hypoxic and diabetic groups compared with control subjects $(p<0.001)$. The degree of resistance correlated with arterial oxygen tension at the time of
\end{abstract}

testing $(r=0.72, p<0.01)$. In all individuals with acute exacerbations of hypoxia, the resistance to ischaemia was normalised with improvement of respiratory function $(p<0.02)$. These results are compatible with the hypothesis that endoneurial hypoxia may be a factor in the pathogenesis of diabetic neuropathy.

Key words: Diabetes, neuropathy, hypoxia, ischaemia, ischaemia resistance.
Normal peripheral nerve is rapidly inactivated by ischaemia [1, 2]. One of the constant properties of nerve in diabetes is that, even in the presence of diminished function as measured by other electrophysiological parameters, the nerve is able to function for an abnormally long time after being rendered ischaemic [3]. This property has been observed for many years [4], and is known to be present in Type 1 (insulin-dependent) [5] and Type 2 (non-insulin-dependent) [6] diabetes even at the time of diagnosis, although in Type 1 diabetes it is reported as being reversible with insulin therapy [5]. The degree of resistance to ischaemia has been associated with prevailing glycaemia [7], but the latest study to address this point did not find such a relationship in Type 2 diabetes [6].

Resistance to ischaemic conduction failure (RICF) is one of the recognised abnormalities of animal models of diabetic neuropathy [8], and has been demonstrated in several different models $[9,10]$. The phenomenon has also been described in other metabolic conditions such as uraemia and hepatic failure.

RICF is the earliest abnormality of peripheral nerve function to be observed in diabetes [11], and there are several theories as to how it arises [3]. It has been reported that rearing non-diabetic rats in hypoxic conditions causes neurological abnormalities which are qualitatively similar to those of diabetes, including RICF [8], and that oxygen supplementation prevents the development of RICF in diabetic animals [12]. Although it has also been confirmed that animal [13] and human [14] diabetic peripheral nerve is hypoxic, the actual mechanism of RICF in diabetic patients remains unexplained. In order to investigate further the relationship between oxygen supply and delayed ischaemic inactivation of human peripheral nerve we have studied the degree of RICF in non-diabetic subjects with systemic hypoxia of varying severity.

\section{Subjects and methods}

\section{Patients}

Three groups of patients have been studied.

Group 1. 23 non-diabetic patients with chronic ( $>2$ years) lung disease (chronic obstructive airways disease or emphysema) were studied. Patients were invited to participate in the study if profound hypoxaemia (oxygen tension $\left(\mathrm{PaO}_{2}\right) \leqslant 60 \mathrm{~mm} \mathrm{Hg}(8 \mathrm{kPa})$ ) had been documented in arterial samples. All patients had normal fasting venous blood glucose and glycosylated haemoglobin levels. No other recognised causes of neuropathy were present (no evidence of malignancy, no history of exposure to neurotoxins, normal liver function tests, normal renal function).

Group 2. 23 healthy control subjects matched for age ( \pm 5 years).

Group 3.20 age matched ( \pm 5 years) patients with diabetes, who had established diabetic neuropathy $\geqslant 2$ abnormal electrophysiological parameters plus either diminished ankle reflexes or diminished vibration perception (15)]. None of these patients had a history of respiratory disease.

The study was approved by the Central Manchester Hospitals ethical committee, and was carried out at Manchester Royal Infirmary. Informed consent was obtained from all subjects. 
Table 1. Details of matched groups

\begin{tabular}{llclll}
$\begin{array}{l}\text { Age } \\
\text { (years) }\end{array}$ & $\begin{array}{l}\text { Diabetes } \\
\text { duration } \\
\text { (years) }\end{array}$ & $\begin{array}{c}\text { Retinopathy } \\
\text { nil }\end{array}$ & $\begin{array}{c}\text { Pro- } \\
\text { tein- }\end{array}$ & $\begin{array}{l}\mathrm{HbA}_{1} \\
(\%)\end{array}$ & $\begin{array}{c}\text { Insulin } \\
\text { treated }\end{array}$ \\
& \multicolumn{4}{c}{$\begin{array}{c}\text { uria } \\
\text { prolif. }\end{array}$} \\
\end{tabular}

\begin{tabular}{|c|c|c|c|c|c|c|}
\hline $\begin{array}{l}\text { Group } 1 \\
(n=23) \\
\text { hypoxic }\end{array}$ & $\begin{array}{l}62 \\
(36-73)\end{array}$ & - & --- & - & - & - \\
\hline $\begin{array}{l}\text { Group } 2 \\
(n=23) \\
\text { control }\end{array}$ & $\begin{array}{l}58 \\
(39-70)\end{array}$ & - & --- & - & - & - \\
\hline $\begin{array}{l}\text { Group } 3 \\
(n=20)\end{array}$ & $\begin{array}{l}58 \\
(40-74)\end{array}$ & $\begin{array}{l}14 \\
(1-30)\end{array}$ & $\begin{array}{lll}7 & 4 & 9\end{array}$ & 6 & $\begin{array}{c}10.9 \\
(6.5-13.6)\end{array}$ & 13 \\
\hline
\end{tabular}

Clinical details of patients. Values are given as mean (range) or number in group. Proteinuria: dipstick positive on more than one occasion, glycated haemoglobin $\left(\mathrm{HbA}_{1}\right)$ : non-diabetic range 6-8\%

Table 2. Details of diabetic neuropathic patients

\begin{tabular}{llllll}
\hline & \multicolumn{2}{l}{$\begin{array}{l}\text { Motor conduction } \\
\text { velocity }(\mathrm{m} / \mathrm{s})\end{array}$} & & \multicolumn{2}{l}{$\begin{array}{l}\text { Sensory nerve } \\
\text { amplitude }(\mu \mathrm{V})\end{array}$} \\
\cline { 2 - 2 } & Median & Peroneal & & Median & Sural \\
\hline $\begin{array}{l}\text { Laboratory } \\
\text { normal }\end{array}$ & $\geqslant 50$ & $\geqslant 40$ & & $\geqslant 9$ & $\geqslant 3$ \\
$\begin{array}{l}\text { Diabetic } \\
\text { patients }\end{array}$ & $46.4 \pm 7.4$ & $35.3 \pm 7.8$ & & $6.27 \pm 3.6$ & $1.1 \pm 1.9$ \\
\hline
\end{tabular}

Conventional electrophysiological measures for Group 3. Values are given as mean $\pm \mathrm{SD}$. $\mathrm{m} / \mathrm{s}=$ metres per second, $\mu \mathrm{V}=$ microvolts

Table 3. Details of patients in acute and convalescent study

\begin{tabular}{|c|c|c|c|c|c|c|c|c|c|}
\hline \multirow{2}{*}{$\begin{array}{l}\mathrm{Pa}- \\
\text { tient }\end{array}$} & \multirow{2}{*}{$\begin{array}{l}\text { Age } \\
\text { (years) }\end{array}$} & \multicolumn{4}{|c|}{ Acute } & \multicolumn{4}{|c|}{ Convalescent } \\
\hline & & $\mathrm{PaO}_{2}$ & VPT0 & VPT30 & II & $\mathrm{PaO}_{2}$ & VPT0 & VPT30 & II \\
\hline 1 & 66 & 47 & 15 & 20 & 1.3 & 63 & 12 & 35 & 2.9 \\
\hline 2 & 59 & 38 & 10 & 16 & 1.6 & 59 & 12 & 44 & 3.7 \\
\hline 3 & 61 & 42 & 20 & 27 & 1.35 & 64 & 14 & 34 & 2.4 \\
\hline 4 & 45 & 44 & 10 & 14 & 1.4 & 60 & 8 & 19 & 2.38 \\
\hline 5 & 61 & 51 & 9 & 13 & 1.44 & 80 & 6 & 22 & 3.6 \\
\hline 6 & 59 & 44 & 10 & 10 & 1 & 61 & 10 & 18 & 1.8 \\
\hline 7 & 58 & 47 & 14 & 22 & 1.9 & 69 & 12 & 27 & 2.25 \\
\hline
\end{tabular}

Details of the seven patients who were studied on two occasions. Arterial oxygen tension $\left(\mathrm{PaO}_{2}, \mathrm{~mm} \mathrm{Hg}\right)$. Vibration perception threshold at baseline (VPT0), and at $30 \mathrm{~min}$ (VPT30). Ischaemic index (II) defined as VPT30/VPTO

\section{Methods}

Measurements of resistance to ischaemia were made by an established method [4-7]; assessing the perception threshold for vibration in the foot using a biothesiometer (Bio-Medical Instrument Company, Newbury, Ohio, USA), and then repeating this assessment at 5-min intervals following proximal arterial occlusion, up to $30 \mathrm{~min}$. Arterial occlusion was achieved with a sphygmomanometer cuff inflated to $50 \mathrm{~mm} \mathrm{Hg}$ above brachial systolic pressure, and confirmed with a doppler ultrasound stethoscope. In order to standardise the measure, the ischaemic index (II) [6], defined as the ratio of vibration perception threshold (VPT) at $x \min (\mathrm{VPT} x)$ over the baseline reading (VPT0) was calculated. A minimum of three readings were taken at each measurement of VPT, to ensure consistency.

In seven of the 23 hypoxic patients, who had profound hypoxaemia due to acute exacerbations of their lung disease, but were alert and able to give informed consent and cooperation, we were able to make more than one assessment, after therapeutic intervention had substantially improved arterial oxygenation (interval 4-28 days). Arterial blood gases were measured at the time of testing, where possible.

\section{Statistical analysis}

Statistical analysis was carried out using the 'Amstat' statistical package for Amstrad computers (S.C.Coleman Ltd, Ashby-de-la-Zouch, Leics, UK) and standard non-parametric tests used for all comparisons.

\section{Results}

Clinical details of the groups are given in Table 1. Details of conventional measures of nerve function in Group 3 (diabetic neuropathy) are given in Table 2. Group 1 (hypoxic patients) had abnormal resistance to ischaemic conduction failure compared with control subjects (Mann Whitney U-test, $p<0.001$ ); there was a similar degree of RICF in the diabetic and hypoxic groups (Fig.1). Baseline VPT was within our normal age-matched range in Groups 1 and 2: $15 \pm 4.7$ [mean $\pm \mathrm{SD}$ ], and $11.7 \pm 4.8$ respectively. As expected, VPT was higher in Group 3 (diabetic neuropathy): $24 \pm 7.7$.

There was a significant correlation between the ischaemic index and $\mathrm{PaO}_{2}$ measured at the time of testing $(n=30$, Spearman $r=0.72, p<0.01)$ (Fig. 2). There was a weaker correlation with age $(r=-0.4, p<0.05)$, but age was also associated with more severe hypoxaemia $(r=-0.3, p<0.05)$.

In the 7 patients whom we were able to study on more than one occasion, there was a significant change in the ischaemic index towards normal with improvement of blood gases (randomisation test for matched pairs, $p<0.02$ ) (Table 3 , Fig. 3 a). This change in ratio was due to a change in VPT30 $(p<0.02)$, but not in VPTO (Fig. 3 b).

No significant discomfort or side effects were reported by any patient.

\section{Discussion}

We have demonstrated a direct relationship between RICF and hypoxia in non-diabetic subjects, and shown that the phenomenon is reversible with improvement of oxygenation.

RICF has been associated with diabetes for many years [4], and although this abnormality is more pronounced in those with established neuropathy [6], the 


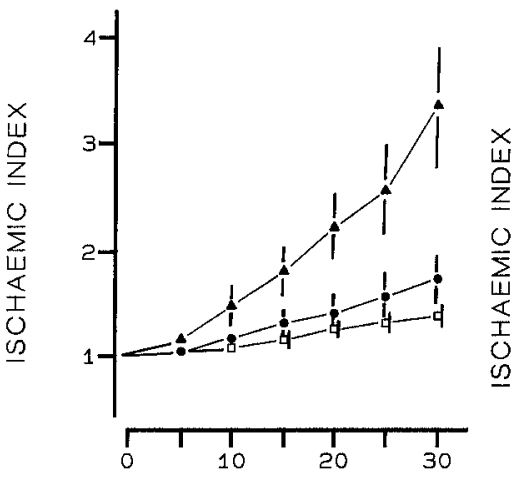

1

Time $(\min )$

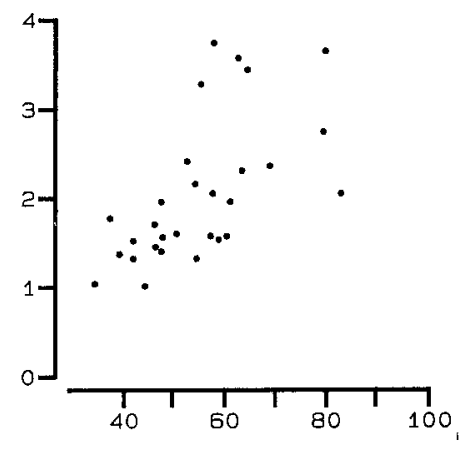

2
Fig.1. Mean and 95\% confidence intervals for vibration perception threshold (VPT) ratios (VPTx/VPT0 = ischaemic index) for the three groups: Control (A); Hypoxic (); Diabetic ( $\square$ ). Hypoxic versus control, $p<0.001$ at $30 \mathrm{~min}$; Diabetic versus control, $p<0.001$ at $30 \mathrm{~min}$; Hypoxic versus diabetic, NS

Fig. 2. Correlation of ischaemic index and arterial oxygen tension $\left(\mathrm{PaO}_{2}\right)(r=0.72, p<0.01)$ Normal range: $\geqslant 2$ question of whether this is also associated with causative factors of neuropathy remains unclear. RICF has also been reported in other metabolic conditions such as uraemia and hepatic failure $[16,17]$ and there may be more than one mechanism responsible for producing the effect. However, although much recent work studying the pathogenesis of diabetic neuropathy has been associated with metabolic theories of aetiology, Jaramillo et al. were unable to demonstrate any association between RICF and the aldose reductase pathway [10]. There has been increasing interest by some workers in the effects of hyperglycaemia on the endoneurial microcirculation, and reduced nerve blood flow has been demonstrated in animal models [13]. Endoneurial oxygen tension has been measured directly in animals [13] and humans [14] with diabetes, and found to be reduced. Oxygen supplementation has prevented RICF in experimental diabetes [12], and hypoxia has produced RICF in non-diabetic animals [8].

The physiological basis for RICF has remained enigmatic. Computer simulation suggests that the metabolic cost of impulse propagation can be reduced if nerve fibres are slightly depolarised [18], and reduction of metabolic demand has been described as the most effective strategy for protecting tissues from the effects of anoxia [19]. Two theories for the cause of RICF in diabetic peripheral nerve were considered in a recent review [3]: (1) that diabetic nerve has increased substrate for anaerobic metabolism, and (2) that chronic endoneurial hypoxia leads to a reduction in endoneurial oxygen demand. The former is supported by certain biochemical changes which have been observed in experimental diabetes [20]; but the fact that it takes an average of 18 days to normalise ischaemic conduction failure in Type 1 diabetes after starting insulin treatment [5] suggests that there may also be reduced energy requirement in peripheral nerve. This would favour the latter theory. Further support for the latter theory is provided by studies in experimental diabetic animals, as RICF can be prevented by oxygen supplementation, in the presence of increased substrate [12]. Moreover, the duration of impulse propagation following anoxia in nerves from different species is directly related to oxygen uptake under normal conditions [21].

Our results in non-diabetic subjects would also support the latter theory of the aetiology of RICF; that it can arise as an adaptation to an hypoxic environment. In the most profoundly hypoxic subjects RICF was universal, with greater scatter as $\mathrm{PaO}_{2}$ rises. Furthermore, the reversibility of the phenomenon with improvement of oxygenation provides further evidence

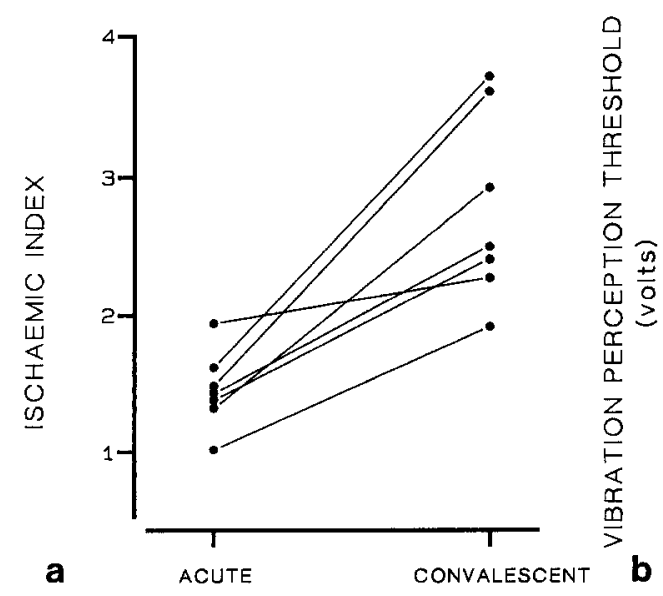

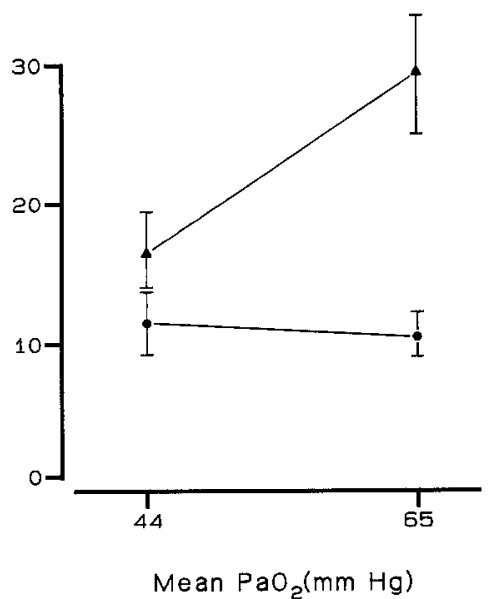

Fig. 3. a Ischaemic index changes with improvement of steady state respiratory function $(p<0.02)$. b Mean and $95 \%$ confidence intervals for vibration perception thresholds in acute and convalescent studies. Threshold at baseline (O), (NS). Threshold at $30 \mathrm{~min}(\mathbf{\Delta}),(p<0.02)$ 
for this view. In some human diabetic subjects without neuropathy, endoneurial oxygen tension has been found to be normal [14], but it was not reported in that study whether the subjects demonstrated resistance to ischaemic conduction failure. However, as many diabetic patients demonstrate some resistance without overt neuropathy, it is possible that both mechanisms described above are important in these patients.

Chronic lung disease leading to profound systemic hypoxia has been known to be associated with peripheral nerve abnormalities for many years, and histological studies have confirmed that structural changes are present $[22,23]$, although such neuropathy is usually subclinical. The implication may be that diabetic peripheral nerve is under hypoxic stress when resistance to ischaemia is evident, and that this stress may contribute to the development of neuropathy. Endoneurial hypoxia in acute experimental diabetes has been shown to be associated with altered microcirculation [13], and structural microangiopathy has been demonstrated in sural nerve biopsies from patients with established neuropathy [24].

In conclusion, our demonstration that resistance to ischaemic conduction failure in non-diabetic subjects is strongly influenced by prevailing arterial, and thus endoneurial oxygenation, supports the theory that hypoxia may be one of the early stresses on the diabetic nerve.

Acknowledgements. We thank Prof. S. Tomlinson for his constant support and encouragement, and Dr. T. B. Stretton for permission to study his patients. EAM and AJMB are supported by the Wellcome Trust.

\section{References}

1. Caruso G, Labianca O, Ferrannini E (1973) Effect of ischaemia on sensory potentials of normal subjects of different ages. $J$ Neurol Neurosurg Psychiatry 36: 455-466

2. Seneviratne KN, Peiris OA (1968) The effect of ischaemia on the excitability of human sensory nerve. J Neurol Neurosurg Psychiatry $31: 338-347$

3. Low PA (1987) Recent advances in the pathogenesis of diabetic neuropathy. Muscle Nerve 10: 121-128

4. Steiness I (1959) Vibration perception in diabetics during arrested blood flow to the limb. Acta Med Scand 163: 195-205

5. Terkildsen AB, Christensen NJ (1971) Reversible nervous abnormalities in juvenile diabetics with recently diagnosed diabetes. Diabetologia 7: 113-117

6. Newrick PG, Boulton AJM, Ward JD (1987) Nerve ischaemia-resistance: an early abnormality in diabetes. Diab Med 4: 517-520

7. Steiness I (1961) Influence of diabetic status on vibratory perception during ischaemia. Acta Med Scand 170: 319-338

8. Low PA, Schmelzer JD, Ward KK, Yao JK (1986) Experimental chronic hypoxic neuropathy: relevance to diabetic neuropathy. Am J Physiol 250: E94-E99
9. Seneviratne KN, Peiris OA (1969) The effects of hypoxia on the excitability of the isolated peripheral nerves of alloxan-diabetic rats. J Neurol Neurosurg Psychiatry 33: 462-469

10. Jaramillo J, Simard-Duquesne N, Dvornik D (1985) Resistance of the diabetic rat nerve to ischaemic inactivation. Can J Physiol Pharmacol 63: 773-777

11. Horowitz SH, Ginsberg-Fellner F (1979) Ischaemia and sensory nerve conduction in diabetes mellitus. Neurology 29: 695-704

12. Low PA, Tuck RR, Dyck PJ, Schmelzer JD, Yao JK (1984) Prevention of some electrophysiologic and biochemical abnormalities with oxygen supplementation in experimental diabetic neuropathy. Proc Natl Acad Sci USA 81: 6894-6898

13. Tuck RR, Schmelzer JD, Low PA (1984) Endoneurial blood flow and oxygen tension in the sciatic nerves of rats with experimental diabetic neuropathy. Brain 107: 935-950

14. Newrick PG, Wilson AJ, Jakubowski J, Boulton AJM, Ward JD (1986) Sural nerve oxygen tension in diabetes. Br Med J 293: 1053-1054

15. Dyck PJ, Karnes J, O'Brien PC (1987) Diagnosis, staging, and classification of diabetic neuropathy. In: Dyck PJ, Thomas PK, Asbury AK, Winegrad AI, Porte D (eds) Diabetic neuropathy. WB Saunders, Philadelphia, pp 36-44

16. Castaigne $\mathrm{P}$, Cathala H-P, Beassart-Boulenge L, Petrover $M$ (1972) Effect of ischaemia on peripheral nerve function in patients with chronic renal failure undergoing dialysis treatment. J Neurol Neurosurg Psychiatry 35: 631-637

17. Nielsen VK, Kardel T (1975) Delayed decrement of the nerve impulse propagation during induced limb ischaemia in chronic hepatic failure. J Neurol Neurosurg Psychiatry 38: 966-976

18. Ritchie JM (1985) A note on the mechanism of resistance to anoxia and ischaemia in pathophysiological mammalian myelinated nerve. J Neurol, Neurosurg, Psychiatry 48: 274-277

19. Hochachka PW, Dunn JF (1983) Metabolic arrest: the most effective means of protecting tissues against hypoxia. In: Sutton JR, Houston CS, Jones NL (eds) Hypoxia, Exercise, and Altitude: Proceedings of the Third Banff International Hypoxia Symposium, Alan R Liss Inc, New York, pp 279-309

20. Low PA, Ward K, Schmelzer JD, Brimijoin S (1985) Ischaemic conduction failure and energy metabolism in experimental diabetic neuropathy. Am J Physiol 248: E457-462

21. Wright EB (1946) A comparative study of the effects of oxygen lack on peripheral nerve. Am J Physiol 147: 78-89

22. Appenzeller O, Parks RD, MacGee J (1968) Peripheral neuropathy in chronic disease of the respiratory tract. Am $\mathbf{J}$ Med 44: $873-880$

23. Paramelle B, Vila A, Pollak P, Muller P, Gavelle D, Reymond F, Brambilla C, Stoebner P (1986) Frequence des polyneuropathies dans les bronchopneumopathies chroniques obstructives. Presse Medicale 15: 563-567

24. Yasuda H, Dyck PJ (1987) Abnormalities of endoneurial microvessels and sural nerve pathology in diabetic neuropathy. Neurology $37: 20-28$

Received: 25 April 1988

and in revised form: 30 June 1988

Dr. A.J. M. Boulton

Department of Medicine

Manchester Royal Infirmary

Oxford Road

Manchester M13 9WL

UK 